\title{
Depois da democracia racial
}

Antonio Sérgio Alfredo Guimarães

Afinal, o que éa democracia racial brasileira? D epois de denunciada como mito (cf. Fernandes, 1965) e transformada, nos anos de 1980, no principal al vo dosataques do movimento negro, como sendo umaideologia racista ${ }^{1}$, a "democracia racial" passou na última década a ser objeto de investigação mais sistemática decientistas sociais ehistoriadores. A princípio, prevaleceu a compreensão de que se tratava real mente de um mito fundador da nacionalidade. Afinal, o Brasil teria sido percebido historicamente como um país onde os brancos tinham uma fraca, ou quasenenhuma, consciência de raça (cf. Freyre, 1933); ondea miscigenação era, desdeo período colonial, disseminada e moral mente consentida; onde os mestiços, desde que bem-educados, seriam regularmente incorporadosàs elites ${ }^{2}$; enfim, ondeo preconceito racial nunca fora forte o suficiente para criar uma "linha de cor". Viotti da Costa (1985) fez talvez a mais completa síntese dessa interpretação.

Em meados dos anos de 1990, com o recrudescimento dos ataques dos ativistas negrosà "democracia racial" e à sua redução a ideologia dominante (e da raça opressora), alguns antropólogos (cf. M aggie, 1996; Fry, 19951996; Schwarcz, 1999) lembraram que o mito, antes de ser uma "falsa consciência", éum conjunto de val ores que tem efeitos concretos nas práticas dos indivíduos. 0 mito da democracia racial, portanto, não poderia ser interpretado apenas como "ilusão", pois em grande medida fora e ainda é um ideário importante para amainar e coibir preconceitos.
1. N ão apenasosativistas, mas eu mesmo escrevi: "N os anos de ditadura militar, entre 1968 e 1978, a 'democracia racial' passou a ser um dogma, uma espécie de ideologia do Estado brasileiro. 0 ra, a redução do anti-racismo ao anti-racialismo, e sua utilização para negar os fatos de discriminação e as desigualdades raciais, crescentes no país, acabaram por formar uma ideologia racista, ou seja, uma justificativa da ordem discriminatória e das desigualdades raciais realmente existentes" (Guimarães, 1999, p. 62). Ronaldo 
Sales Jr., nesse número, desenvolve essa argumentação.

2. 0 sestudosderelações raciais de 1940 a 1960 corroboraramessavisão. Ver, entre outros, Pierson ([1942]1971); Azevedo (1953); Wagley (1952); H arris (1956).

3.Entendo por "consentimento", à maneiradePrzeworski (1985, p. 146), o comportamento coletivo em que os "negros agem esperando melhorar sua condição material de vida seguindo as regras sociais dadas. "Coope ração consiste em utilizar-se de estratégias e ameaças conhecidas pelo oponente no curso da negociação." N 0 compromisso, o consentimento das organizações negras à democracia representativa é possível em troca da perspectiva de integração social edemelhoria material de vida.

4. Passo, de agora em diante, aempregar apalavra "regime" no sentido de "regime de Estado" que Ihe dá Barth (1994).
Em sucessivas aproximações (ff. Guimarães2001; 2002; 2003), introduzi outro elemento no debate. Contra a tendência a interpretar a "democracia racial" como um mito atemporal, fundador da nacionalidade, procurei demarcar historicamente o seu surgimento, aferrando-me à investigação do aparecimento da expressão "democracia racial" em vez de buscar a origem histórica dasidéias quea compõem. Separei, assim, analiticamente, o queera chamado pelos historiadores de "paraíso racial", um conjunto de crenças na ausência de preconceitos de raça no Brasil, que pode ser retraçado ao Impé rio, do mesmo conjunto de crenças que reivindicava para o Brasil não aimagem de paraíso, mas de democracia. Os estudos de Campos (2002; 2006), reforçando minha argumentação, revelaram depois que a expressão surge disseminadamente entre os intelectuais brasileiros na conjuntura de 19371944, ou seja, duranteo Estado N ovo, diante do enorme desafio deinserir o Brasil no mundo livre edemocrático, por oposição ao racismo e ao totalitarismo nazi-fascistas, que acabaram vencidosnaSegunda G rande G uerra.

Essa mudança no modo de entender "democracia racial" nos permite estudá-la não apenas como mito, ou seja, como construção cultural, mas também como "cooperação", "consentimento" ou "compromisso" políti$\mathrm{CO}^{3}$. M ais que uma ideologia, ela foi um modo tacitamente pactuado de integração dos negros à sociedade de classes do Brasil pós-guerra, para utilizar o famoso título de Florestan, tanto em termos de simbologia nacional, como em termos da sua política econômica e social. M as esse foi um compromisso duplamentelimitado: por um lado, incluía apenas os trabalhadores das cidades, deixando de fora não apenas outros segmentos populares urbanos, como por exemplo os empregados domésticos, mas todos os trabalhadores do campo; por outro lado, era um pacto de poder restringido pelo fato de não haver espaço para o reconhecimento de formaçōes étnicoraciais que pretendessem participar do sistema político. D e fato, o sistema político fora concebido e funcionava guiado por princípios universalistas genéricos, que desconsideravam pertenças sociais espeć́ficas, enquanto na prática, ou seja, no nível do regi met, tratava-se de relacionar sindicatos, associações e lideranças de comunidades locais, geralmente de vizinhanç̧a, a líderes políticos e seus partidos.

D esenvolvi alhures (cf. Guimarães, 2002) o modo como o compromisso político se desfez com o gol pe militar de 1964, a implantação do regime autoritário que se seguiu e a conjuntura política internacional dos anos de 1970, influenciada pela bem-sucedida montagem deuma ordem multirracial nos Estados U nidos. Retomemos, em linhas gerais, como isso ocorreu. 
Um dos traços peculiares do compromisso democrático, do ponto de vista ideológico, era a mobilização de intelectuais contra o personalismo e o mandonismo das oligarquias. Com efeito, a modernização dos costumes e a moralização das práticas políticas foram ideais perseguidos tanto ao centro como à esquerda do espectro político. 0 preconceito racial era entendido pelos sociólogos dos anos de 1960 (cf. Azevedo, 1953; Bastide e Fernandes, 1955; Fernandes, 1965) como característico dos privilégios do regime de castas (cf. Wagley, 1952) ou do patrimonialismo brasileiro (cf. Faoro, 1958). Todos pensavam (ou desejavam?) que ele e as desigualdades oriundas do escravismo deveriam ser eficazmente combatidos com a universalização das oportunidades de vida (educação e saúde, principalmente) e com garantias à competição por mérito em mercados livres de particularismos sociais, culturais, políticos ou biológicos. Como acontecera antes na Europa ocidental e nos Estados U nidos (revoluções inglesa, francesa e americana), tratava-se de implantar a democracia por meio de uma revolução (cf. H olanda, 1936; Wagley, 1960) que alijasse do poder a classe senhorial e estabelecesse uma democracia representativa cujo alicerce estivesse assentado sobre as classes produtoras e trabal hadoras urbanas. O s negros e mulatos, portanto, entravam politicamente no compromisso democrático como povo, como trabalhadores e como intelectuais. N essa leitura, o texto de M uryatan Barbosa, neste número, é esclarecedor do modo como o universalismo de Guerreiro Ramos funde-se com a identidade diaspórica da negritude, para forjar um nacionalismo peculiar.

0 regime militar entre 1964 e 1985 rompeu com alguns pressupostos desse compromisso, mas não todos. A universal ização das oportunidades de vida e o combate à corrupção que empanava a competição por mérito foram, por exemplo, bandeiras de primeira ordem do regime autoritário.

Tomemos como exemplo o que se passou no ensino superior do país, al go que nos interessa particularmente por conta das atuais reivindicações de cotas, tratadas por G raziella Silva neste número. As reformas educacionais do período militar visaram, sobretudo, a ampliar o sistema educacional como um todo, universalizar o ensino primário e médio e, por meio da instituição de exames vestibulares unificados, classificatórios e objetivos (provas de múltipla escolha), assegurar que o ingresso às universidades se daria unicamente pelo desempenho nas provas. 0 ensino público universitário manteve-se gratuito, embora a ampliação do ensino superior passasse a depender, principal mente, da criação de universidades privadas e pagas. Já em meados dos anos de 1970, as conseqüências dessas escolhas faziam-se 
sentir: a proliferação de cursinhos particulares pré-vestibulares, a ampliação da rede privada de ensino primário e médio, a transferência dos filhos das classes médias para essas escolas. 0 acesso às melhores universidades passou, portanto, a associar-se com o ensino médio particular e pago, e não mais com o ensino público. Isso significou também associar o ingresso a essas universidades a rendas familiares mais altas e a cor de pele mais clara. Boa parte da população universitária na rede particular, aquela de menor desempenho, veio principalmente de escolas médias públicas, onde estudavam os de menor renda e os de cor.

Fracassaram politicamente todos os esforços de tornar pago, para as famílias de renda alta, o ensino superior público, o que daria al guma margem a programas de inclusão social baseados em bolsas de estudo ou em isenções de taxas, que conservariam a legitimidade e o mérito dos exames vestibulares. Ao contrário, o ingresso em universidades de escol, como a U niversidade de São Paulo, passou a depender cada vez mais de formação em escolas pagas. Em 2006, por exemplo, apenas $27 \%$ dosalunos queingressaram na U SP vieram de escolas públicas. Com isso acentuou-se a rigidez da reprodução social das elites, voltando-se a associar classe, cor e oportunidades públicas de ascensão a níveis próximos, ao menos relativamente, aos da Primeira República.

0 multiculturalismo no Brasil e na América Latina

Grande parte dos países da América Latina passou por ampla reforma constitucional nos anos de 1980 e 1990. Isso pode ser explicado em grande medida pela reconstrução do Estado democrático de di rei to depois das duas décadas de autoritarismo que assolaram o continente, de meados dos anos de1960 atémeados da década de 1980. A reconstrução não foi idênticaà do pós-guerra, entretanto, no sentido de queo ideário democrático eliberal dos anos de 1980 diferia em muito daquele dos anos de 1940. A semelhança deu-se no fato de que, de novo, os países da região buscavam se espelhar na Europa enos Estados U nidos para reconstruir seus modelos democráticos.

M as, entre os anos de 1940 e de 1980, mudaram pelo menos dois importantes paradigmas: 0 de nação e o de direitos civis. Primeiro, já não dominava mais internacionalmenteo modelo de construção nacional nascido no século XIX, segundo o qual as nações eram comunidades de pertença cultural, lingüística e racial homogêneas. Ao contrário, preval ecem agora os paradigmas do multiculturalismo e do multirracial ismo, pel os quais o 
Estado deve preservar e garantir a diversidade lingüística e cultural de seus cidadãos. Segundo, democracia já não poderia ser entendida em termos estritamente liberais, como igualdade formal dos cidadãos e garantia das liberdades individuais. Nos dias atuais, idéias como a de direitos coletivos, a de que há grupos sociais e coletividades que devem ter garantida a igualdade de oportunidades, assim como a idéia de que tal igual dade deve se refletir em termos de resultados, são correntemente aceitas internacionalmente.

As reformas constitucionais recentes na América Latina, portanto, no que toca às identidades raciais, trouxeram como novidade a concepção de sociedades e nações pluriétnicas e multiculturais. Tais constituições submergiram, assim, o ideal fundador de nações mestiças e culturalmente homogêneas, vistas como produto da miscigenação biológica e cultural entre europeus, indígenas americanos e africanos, ideal cuidadosa e trabal hosamente gestado desde as guerras de independência do século XIX.

Países como Argentina, Bolívia, Brasil, Chile, Colômbia, Costa Rica, Equador, Guatemala, H onduras, M éxico, Nicarágua, Panamá, Paraguai, Peru e Venezuela reconheceram em suas novas Constituições os direitos históricos das suas minorias indígenas. 0 utros passaram a reconhecer direitos coletivos ou adotar formas de discriminação positiva para minorias negras, tais como o Brasil (Constituição de 1988, Lei 7.716, Cotas nas universidades, 2001), a Colômbia (C onstituição de 1991 e lei 70 de 1993), 0 Equador (C onstituição de 1998), H onduras, Guatemala e N icarágua.

Segundo D onnaVan Cott (2000), essemodelo constitucional, quepode ser chamado de multicultural, tem as seguintes características: 1) reconhecimento formal da natureza multicultural de suas sociedades e da existência de povos indígenas como coletividades sociais e subestatais distintas; 2) reconhecimento das leis consuetudinárias dos povos indígenas como leis públicas e oficiais; 3) direito à propriedade coletiva com restrição à alienação ou divisão de terras comunitárias; 4) status oficial para línguas indígenas em unidades territoriais de residência; e5) garantia à educação bilíngüe. No caso brasileiro, precisaríamos acrescentar um sexto elemento ao modelo: reconhecimento do racismo como um problema nacional.

$0 \mathrm{ra}$, essas reformas constitucionais foram quase que imediatamente seguidas ou ocorreram concomitantementeà introdução de políticas neoliberais, no campo social e econômico. 0 u seja, a redemocratização acompanhou, como não poderia deixar de ser, a reintegração das economias latino-americanasà nova economia mundial, depois da crise de acumulação 
dos anos de 1980. Tal concomitância da effera política estatal e econômica ensejou al gumas interpretações, que devem ser mencionadas.

A primeira delas (Brysk eW ise 1997; Yashar, 1999) é de que foram as reformas neoliberais dos anos de 1980 que deslancharam a reforma constitucional. Para esses autores, as reformas neoliberais ameaçaram a autonomia local, o que acarretou protestos e mobilização étnica. As reformas do Estado, outorgando direitos culturais, foram a resposta estatal a essa mobilização. Esses autores, diga-se de passagem, estudaram principalmente Estados centro-americanos.

N uma linha interpretativa ligeiramente diferente, Van Cott (2000) argumentou que o multiculturalismo teria sido um meio de as elites políticas reconquistarem a legitimidade corroída por reformas econômicas e as crescentes demandas sociais. $\mathrm{H}$ ale (2002) preferiu argumentar que os Estados latino-americanos estariam reconhecendo ou cedendo direitos às suas minorias indígenas e negras como uma maneira de deslegitimar demandas mais radicais, que atentariam contra a ordem econômica neoliberal. H ooker, que republicamos neste dossiê, por seu turno, comparando os avanços de reconhecimento dessas duas minorias, argumenta que os indígenas tiveram mais facilidadeem obter esses direi tos coletivos que os negros porque historicamente foram definidos como pertencentes a outra cultura. Afirma ela, neste número:

Argumentarei que o principal critério empregado para determinar os beneficiários foi a posse de uma identidade cultural de grupo distinta. Além disso, em razão das diferentes maneiras pelas quais os dois grupos foram racializados na América Latina, a utilização de uma identidade de grupo distinta, concebida de forma étnica ou cultural, como critério para a concessão de direitos coletivos, permitiu que os indígenas fossem mais bem-sucedidos do que os afro-descendentes na reivindicação de tais direitos.

0 fato é, contudo, que o maior ou menor reconhecimento obtido pelas minorias étnicas latino-americanas no período de redemocratização dos anos de 1980 dependeu, principalmente, de fatores que poderemos dispor em dois grupos: as condições internas a cada país e as condições externas ou internacionais.

D e um modo geral, podemos dizer que as características assumidas pelos movimentos negros que, na América Latina, lutaram por reconhecimento étnico ou racial dependem principalmente, no plano interno, de 
dois fatores: das tradições locais que são mobilizadas e das características dos seus contextos políticos e demográficos ${ }^{5}$.

As diferenças demográficas entre esses países não explicam, entretanto, o fato mais intrigante de todos: 0 de que apenas no Brasil a mobilização política teve como objetivo a luta contra desigualdades raciais, enquanto em todos os outros as mobilizações tiveram como alvo principal o reconhecimento da diversidade cultural dos negros, que acompanhavam assim, com atraso, o movimento indígena. Compreendese que, no que se refere aos indígenas, o colapso teórico e ideológico entre "raça" e "etnia" tenha sido sempre a tônica da colonização européia nas Américas, inclusive no Brasil, como bem lembrou Van Cott, o que aproximou naturalmente os mundos anglo-saxão e latino-americano.

No caso dos negros brasileiros, entretanto, a prática duradoura de incorporação de tradições africanas às culturas nacionais inibiu historicamente mobilizações de origem étnico-cultural efavoreceu aquelas puramenteraciais (ou seja, aquelas que se pautavam pelo combate às conseqüências sociais do preconceito e da discriminação raciais). Em que circunstâncias internacionais se deram tais mobilizações?

Em primeiro lugar, há de se mencionar as mudanças de regime de Estado ocorridas nos anos de 1980. As ditaduras militares do Cone Sul, por exemplo, foram substituídas por democracias representativas, que buscaram novas formas de legitimidade internacional para seus países. Em seguida, relacionada à primeira, a integração à ordem econômica internacional dessas novas democracias deu-se em novo regime de acumulação, que ficou conhecido como neoliberalismo. Arrematando o enunciado dessas circunstâncias externas, convém mencionar três outras de ordem mais cultural e ideológica: 1) a doutrina do multiculturalismo torna-se vitoriosa na luta contra o racismo nos Estados U nidos, na África do Sul e nos países anglosaxônicos; 2) a luta pela garantia dos direitos humanos ganha proeminência internacional, o que se transforma, para os negros, em luta contra o racismo; e, finalmente, 3) a importância que assumiram a ecologia, a defesa do meio ambiente e a diversidade biológica e cultural para as agências internacionais de fomento.

O s regimes que entram em crise na América Latina, nos anos de 1970, eram, na maioria, Estados autoritários nacional-desenvolvimentistas, que resolveram sua crise anterior de legitimidade fortalecendo a identidade de nações mestiças e de democracias raciais. 0 ra, na conjuntura de redemocratização dos anos de 1980, as oposições políticas e o povo em geral foram

5. Emtermosdemográficos, os países latinoamericanos que tiveram alguma presença negra podem ser classificados em pelo menos quatro grupos: 1) países com grande população negraecom grandetradição cultural de origem africana, como Brasil eC uba; 2) países negros como $\mathrm{H}$ aiti e Santo D omingo; 3) países com importantes minorias negras, como Colômbia, Venezuela e Equador; 4) países com escassapopulação emobilização negras, como M éxico, Peru, U ruguai eArgentina. 
buscar para a democracia um significado mais radical, mais igualitário em termos de redistribuição de riquezas e de oportunidades de vida.

0 multiculturalismo eas políticas de identidade eram práticas ideológicas que estavam disponíveis no mercado internacional de idéias no momento mesmo em queas novas democracias latino-americanas escreviam as suas constituições. É nesse sentido que C hristian Gros (2000) afirmou que o multiculturalismo está para o neoliberalismo assim como a democracia racial esteve para o nacional-desenvolvimentismo.

0 novo Estado mínimo

Ainda que o Brasil não tenha conhecido nunca o Estado de Bem-Estar Social, a verdade é que as conquistas que os trabalhadores urbanos ameaIharam desde Vargas, em termos de previdência, legislação trabal hista, educação e saúde públicas etc., serviram de modelo para todas as mobilizações e reivindicações populares desde os anos de 1930. Por parte do Estado, foi também a política de compromissos de classes que serviu de modelo para 0 atendimento das demandas vindas dos setores populares, organizados na forma de movimentos sociais, inclusive as organizações negras. Em geral, a absorção das demandas populares se deu pela ampliação da legislação previdenciária ou trabal hista para incluir novasáreas geográficas, novos contingentes populacionais, ou pelo simples crescimento do aparelho estatal, estendendo-o para novas áreas e pondo-o a serviço de um maior número de grupos sociais.

N o caso da população negra, a democracia racial condensou um compromisso, como salientei acima, quetinha duas vertentes, uma material eoutra simbólica. M aterialmente, a ampliação do mercado de trabal ho urbano absorveu grandes contingentes de trabal hadores pretos e pardos, incorporando-os definitivamente às classes operárias e populares urbanas. Incorporação que foi institucionalizada por leis como a de Amparo ao Trabalhador Brasileiro N ato, assinada por Vargas em 1931, que garantia que dois terços dos empregados em estabelecimentos industriais fossem brasileiros natos; ou a lei Afonso Arinos, de 1951, que transformava o preconceito racial em contravenção penal. Simbolicamente, o ideal modernista de uma nação mestiça foi absorvido pelo Estado e as manifestações artísticas, folclóricas e simbólicas dosnegros brasileiros foram reconhecidas como cultura afro-brasileira. 0 "afro", entretanto, designava apenas a origem de uma cultura que, antes detudo, era definida como regional, mestiça e, como o próprio negro, 
crioula. A ideologia política da democraciaracial, como pacto social, foi predominantemente o trabal hismo, tendência que data da Primeira República (ver, por exemplo, a ideologia deum $M$ anoel Q uerino) equefoi continuada por novas lideranças, como Abdias do $\mathrm{N}$ ascimento ${ }^{6}$.

Vimos que o regime militar, a partir de 1964, ainda que mantivesse a democracia racial em sua vertente material e simbólica, procurou retirar dela qualquer substrato político, ao reprimir pela força a vida sindical e associativa, e seus elos informais e formais com os partidos políticos. 0 pacto desfez-se, portanto, junto com a democracia representativa e o Estado nacional-desenvolvimentista.

Restabelecida a vida democrática em 1985, o Estado tentará por um curto tempo restabelecer 0 antigo jogo de classes, tentando relacionar-se com os novos movimentos sociais a partir dos partidos políticos, da ampliação do seu próprio aparelho e do aggiornamiento de sua legislação. Em relação à população negra, a atualização legal deu-se com a criminalização do racismo pela Constituição de 1988, regulamentada pela lei 7.716, de 1989; enquanto os marcos simbólicos principais foram a criação da Fundação Cultural Palmares, em 1988, e a instituição de Zumbi como herói nacional, em 1995.

0 próprio ativismo negro, por um breve período, voltou a florescer de modo articulado à política de classes, tal como encenada pelos movimentos sociais e respaldada pelos partidos políticos, principalmente o PT, 0 PDT e o PM DB, e depois o PSD B. A partir de 1988, entretanto, crescentemente, o movimento negro passará a tomar a forma de uma constelação de organizações não-governamentais, financeira, ideológica e politicamente autônomas.

M uitas das novas $0 \mathrm{~N}$ G s negras se afastam tanto do antigo trabal hismo, representado agora pelo PDT, como do novo, representado pelo PT. G estase a fusão de duas tendências que, no Brasil, pareciam opostas: a busca de maior integração e partici pação na vida nacional ea construção de um sentimento étnico, baseado na consciência racial. M esmo que se possa traçar uma distinção nítida entre 0 N G s políticas e culturais, dificilmente se encontram hoje entidades culturais negras que não defendam alguma forma de ação afirmativa na área social, assim como dificilmente uma organização política negra deixa de embeber seu discurso no que se chama hoje de "cultura negra".

Por outro lado, a partir do governo Collor, em 1990, o Estado brasileiro passa a assumir explicitamente um discurso mais liberal. 0 seu objetivo
6. Sobre $\mathrm{M}$ anoel Q uerino, ver a biografia de Leal (2004); sobre Abdias do N ascimento, ver Police (2000), $\mathrm{N}$ ascimento (2003) e M acedo (2006). 
passa a ser reestruturar os aparelhos governamentais, procurando livrar-se de muitas das funções do antigo Estado nacional-desenvolvimentista econcentrando-se sobretudo na reforma dos sistemas previdenciário, trabalhista, educacional e de saúde, de modo a descolar a gestão da economia da gestão da política social. O s órgãos de planejamento estatal são enxugados com a finalidade de expulsar dos aparelhos estatais o conflito político de redistribuição de riqueza, e muitas das funções de assistência e de atendimento sociais do Estado são passadas para O N G s e empresas privadas, principalmente na forma de parcerias.

Tal redirecionamento dos aparelhos de Estado acaba por fortalecer as O N G s em geral, e as negras em particular, que avançam enormemente no atendimento às populações carentes, oferecendo serviços os mais diversos, mormentenas áreas de educação, saúde, lazer eadvocacia de direitos humanos. Consolida-se também, por essa via, o que fora gestado na expansão da educação superior: uma ampla camada intelectual negra, formada por quadros profissionais de nível superior, em grande parte autônoma em relação ao Estado, que tem como principal fonte de recursos grandes fundações internacionais, igrejas e instituições de direito privado.

Por outro lado, o Estado brasileiro deixa de certo modo de se preocupar com a gestão da política de identidade nacional, retirando-a da pauta dos M inistérios da Educação eda Cultura. Adota um discurso de multiculturalismo e passa aos agentes não-governamentais a responsabilidade e a liberdade degerenciá-la.

No meu entender, a culminação desse tipo de Estado mínimo dá-se no governo Lula, quando o Estado procura absorver em grande parte as reivindicações dos movimentos sociais por meio da incorporação de seus quadros aos aparelhos estatais, tornando mais fluida a comunicação entre Estado e $0 \mathrm{~N} \mathrm{G}$ s, ao mesmo tempo em que mantém a política econômica totalmente desvinculada do atendimento às demandas populares. Isso talvez explique por que o Partido dos Trabalhadores, que durante o tempo que esteve na oposição foi tão refratário às ações afirmativas e às políticas de identidade não-classistas, tidas como políticas burguesas, tenha, uma vez no poder, transformado seu governo no que mais avançou no atendimento à agenda das organizações negras.

0 novo regime neoliberal incentiva, assim, a autonomia das $0 \mathrm{~N} \mathrm{G}$ s; ao contrário do antigo regime nacional-desenvolvimentista, que favorecia compromissos políticos, forçando o Estado a atender as reivindicações dos movimentos sociais e criando, para tanto, elos diretos entre, de um lado, 
seus aparelhos e quadros, e, de outro, os quadros e aparelhos das organizações partidárias ou associativas. $N$ aquelesidos, os movimentos perdiam al go desua ideologia própria, partedeseu idioma étnico, para ajustar-seà ideologia nacional; no momento atual, o Estado abdica deseu discurso nacionalista em favor de uma multiplicidade de idiomas e de identidades que se harmonizam a partir deregras de convivência social e democrática, sintetizados nosdireitos da cidadania. 0 que Gramsci chamou detransformismo, ou seja, a absorção pelo Estado dos quadros dos movimentos sociais, que gerava uma espécie derotinização das reivindicações sociais, despindo-as de potencial revolucionário, foi substituído pela autonomia relativa de todos os agentes políticos, cuja incorporação ao sistema éautomática: aregra geral do regimeéa partici pação no jogo democrático do Estado dedireito, guardadas todas as especificidades não necessárias ao jogo.

0 regime anterior podia atender as reivindicações dos movimentos negros (principalmente o combate às discriminações e ao preconceito raciais) destituindo-os de linguagem étnica e integrando-os simbolicamente à nação. Podia também, na cena internacional, brandir a ideologia da democracia racial como a solução mais civilizada para superar o problema real das desigualdades na distribuição de riquezas e de oportunidades, entre negros e brancos.

O ra, as lideranças negras, desde a ruptura democrática de 1964, passaram a duvidar da efetividade da democracia racial. Em substituição, começaram a expressar suas queixas em linguagem étnica. 0 que sabemos hojeé que essa linguagem fusiona os elementos tradicionais da identidade afrobrasileira às ideologias negras de circulação internacional, tais como o panafricanismo, a negritude e 0 afrocentrismo.

$M$ as nem a formação de uma nova linguagem, nem o novo regime de Estado, evidentemente, explicam tudo. A maior parte do que foi conseguido pelo movimento, em termos de cotas para o ensino universitário, por exemplo, se deu em instâncias autônomas de poder, como as universidades federais. Em algumas delas, ativistas negros, na condição de representantes do movimento social, chegam mesmo a participar do processo de seleção dos alunos cotistas.

Fica por investigar, portanto, o modo como as bandeiras do movimento negro, principalmente as cotas para negros nas universidades, ganharam 0 apoio de políticos, tecnocratas e autoridades universitárias. 0 u seja, como e por que o multiculturalismo torna-se uma ideologia dominante em várias esferas do Estado. 
H oje, para muitos (cf. Petruccelli, 2006), o multiculturalismo éa ideologia apropriada ao Estado contemporâneo, que necessita reconhecer as novas identidades sociais baseadas na raça e na cultura, ou seja, os novos grupos sociais e atores políticos (os negros, os indígenas etc.). 0 Estado precisa nomear e mensurar as diferenças e as desigualdades sociais prejudiciais a esses grupos se pretende ser um bom governo. Para outros (cf. Carvalho, 2004), o multiculturalismo é uma ideologia profundamente contrária ao espírito que norteou a formação histórica da nação brasileira. M ais que isso: argumentam queas políticas de cotas desembocariam necessariamente no funcionamento de comissões julgadoras para decidir sobre a "cor" ou a "etnia" de um possível beneficiário, deixando patentes duas coisas: que a "cor" ou a "etnia" têm caráter menos sólido e menos consensual, em termos sociológicos, do que o requerido para critérios de seleção de benefícios; e que o direito individual de nomear-se ou auto-representar-seé conseqüentemente desrespeitado.

N o Brasil atual, ganha força a corrente de opinião que defende que as desigualdades raciais, ou seja, as desigualdades sociais atribuíveis à idéia de raça e à forma como as pessoas se classificam ou são classificadas racialmente, só podem ser combatidas com ações e políticas que reforcem essas identidades raciais. 0 u seja, as políticas de ações afirmativas requereriam políticas de identidade.

A reprodução das desigualdades em diferentes regimes de Estado

* A data entre colche tes refere-se à edição original. Elaéindicada na primeira vez que a obra é citada. N as demais, indica-se somente a edição utilizada pelo autor (N.E.).
0 argumento de que as desigual dades sociais no Brasil estão amarradas a mecanismos invisíveis (ou invisibilizados) de discriminação racial, que favorecem a sua reprodução ampliada, passou paulatinamentea ser consensual, atingindo na última década não apenas o espaço público onde atuam os movimentos sociais, mas os próprios organismos de planejamento governamental. 0 argumento do "círculo cumulativo de desigualdades" foi construído originalmentepelos sociólogos C arlosH asenbalg ([1979] $\left.{ }^{*} 2005\right)$ e N elson do Valle Silva (1978), no final dos anos de 1970. Com base na análise dos dados censitários (ou deamostras domiciliares) de renda, educação, naturalidade, origem rural ou urbana, ocupação, ocupação dos pais, estado de residência, cor e outros, eles demonstraram, de modo estatisticamenteirreprochável, quea cor dos indivíduos tinha grande peso na explicação da pobreza e na sua reprodução. A pobreza teria, portanto, as cores preta e parda. 
0 argumento político conseqüente foi de que a simples universalização da educação formal, a ausência de barrei ras raciais legais e a ampliação das oportunidades de emprego e renda, trazidas pelo avanço capitalista, não seriam suficientes para diminuir as desigual dades sociais brasileiras, visto que elas tinham um caráter racial implícito e não visível, que impedia qualquer ilusão de universalização das oportunidades. A democracia racial era realmente um mito e uma farsa, tal como algumas lideranças negras e alguns sociólogos já diziam desde o final dos anos de 1960 (depois do golpe militar). $\mathrm{C}$ arlos $\mathrm{H}$ asenbal g, na entrevista que publicamos neste número, reitera esses argumentos.

Tal conseqüência política, aliás, já tinha sido adotada por diversos atores sociais e políticos, em sua maioria jovens universitários negros que, beneficiando-se do boom dos anos de 1970, fizeram seus estudos superiores e encontravam resistências raciais e culturais à sua absorção em mercados que se haviam formado como nichos de brancos - mídia, escolas e universidades, por exemplo (cf. Santos, 1985); além deativistas dedireitos civisnão detodo à vontade com explicações exclusivamente derivadas do marxismo.

Foi assim quealuta contra a discriminação racial inscreveu-se desdecedo no movimento de luta pela redemocratização do país. A resistência democrática ganha força no final dos anos de 1970 edeságua naadoção decapítulos e leis anti-racistas emulticulturalistas, seja na Constituição, seja nas leis, duranteosanos de 1980 e 1990.

0 cenário que esbocei serve para discutirmos a proposição (cf. Tilly, 2003a; 2003b) segundo a qual as desigualdades sociais (no caso as desigualdades raciais) poderiam entrincheirar-se na sociedade brasileira atual graças ao uso de políticas públicas que passem a categorizar ea "criar" grupos com baseem rótulos raciais. Principalmente tendo em vista queagora, em 2006, pelo menos trinta universidades públicas já adotaram cotas para negros ou alguma outra forma de ação afirmativa.

O ra, dois dos argumentos mais ouvidos no Brasil de pessoas contrárias à adoção de políticas de ação afirmativa que beneficiem os negros seguem de perto 0 esquema causal avançado por Tilly. Primeiro, a imposição estatal de categorias classificatórias baseadas em pertenças raciais levaria à racialização da sociedade brasileira, ou seja, à fixação da idéia de raça, nos discursos públicos e privados, como identidade social, reforçando o ciclo de racismo por acaso existente; segundo, que tal categorização dos brasileiros em brancos e negros (ou não-brancos) é um "empréstimo" infeliz aos nossos vizinhos do $\mathrm{N}$ orte. 
7. Aqui cabe observar também que o modelo causal deTilly émoralmentecarregado designificados: "imposição", por exemplo, é um ato de força, quando não autoritário; "resistência" é um ato de defesa a uma agressão; "empréstimo" éalgo não autêntico e, portanto, despre zível na tradição romântica que preza autenticidade das culturas na cionais e locais.
U ma observação preliminar a ser feita édeque, paraT illy, a "imposição", governamental ou não, parece vir sempre de um grupo dominante ou a serviço de tal grupo, ao passo que o grupo dominado ocuparia um papel de resistência, defesa ou reação. Aqui, ao contrário, é o grupo dominado que pretensamente se beneficia da imposição e a "resistência" viria de parte do grupo dominante. 0 u seja, se aplicado ao Brasil, o esquema teria um caráter "conservador" aparentementenão desejado por Tilly', mas muito bem notado por J oão Feres (2005), que segue a caracterização feita por H irschman (1991) das estratégias discursivas conservadoras: a "racialização" da sociedadebrasileira, ou seja, a adoção de políticas públicas baseadas em pertenças a grupos raciais, beneficiaria, a longo termo, apenas aos racistas.

D e um modo ou de outro, seja ou não conservadora, trate-se ou não de uma mera estratégia discursiva utilizada por conservadores ou por anti-racistas radicais, a explicação causal avançada por T illy nos põe diante de três questões diferentes: as "raças" no Brasil são ou não um mecanismo de reprodução ampliada das desigualdades sociais, como querem H asenbalg e Silva (1988; 1992), Telles (2003), Soares (2000) e muitos outros? Em caso afirmativo, como combatêlas sem reconhecêlas publicamente como constructos raciais e assim correr o risco de cristalizá-las e reproduzi-las como fatos naturais? H istoricamente, no âmbito da história real dos negros brasileiros, as "raças" e as "estratégias racializadas" de demanda por bens públicos são estranhas à sua tradição? 0 u seja, podese caracterizar o discurso ativista dos últimos anos de demanda de cotas nas universidades públicas, na mídia e nos empregos públicos e privados como simples "empréstimos"?

$H$ istoricamente, as identidades negras no Brasil formaram-se em diálogo com as demais identidades negras nas Américas. N esse contexto, pareceme mais produtiva a idéia de um Atlântico N egro (cf. Gilroy, 1993) por onde circulam pessoas, objetos e idéias, do que o conceito de "empréstimo". D o mesmo modo, a pergunta que me parece mais correta é: por que apenas a partir dos 1980 a idéia de "raça" e de "cultura negra" ganha força entre os ativistas e intelectuais que se consideram negros, e não antes, por exemplo nos anos de pós-guerra, quando o prestígio da negritude francesa foi tão forte no Brasil? Por que apenas nos anos de 1990 a idéia de ação afirmativa parece aplicável ao Brasil, quando desde 1925 os ativistas negros se queixam do "preconceito de cor" que aflige toda a comunidade "negra" brasileira? Q ue consensos discursivos tiveram que ser superados ou rompidos para que tais reivindicações pudessem ser formuladas? 
D o mesmo modo, vimos que a idéia de "democracia racial" não podeser analisada como simples mito, ideal ou ideologia. Temos que nos perguntar sobre o caráter real da "democracia" no Brasil nos anos do pós-guerra (19451964); nos anos da ditadura militar (1964-1985) e da N ova República (depois de 1985). Teria a "democracia" o mesmo sentido, despertaria as mesmas expectativas, nutriria as mesmas esperanças e aspirações nos três períodos?

M eu argumento, em grande medida, apóia-se na hipótese de que foi a mudança das aspirações contidas nas democracias de hoje, baseadas principalmentena promessa de direitoscivis, sociaise políticosplenos, paratodos, queacabou por retirar o apelo inicial das "democracias raciais" latino-americanas. Estas tinham seu nódulo central na ausência de barreiras legais ou violentas à mobilidade social dos "homens de cor", por contrasteà segmentação hierárquica herdada da escravidão e do período colonial. As novas democracias que se reinstituem a partir dos anos de 1980, ao contrário, terão que oferecer direitos multiculturais e reconhecer diferenças raciais de modo a acomodar expectativas de integração, de mobilidade e de igual dade que, alternativamente, só poderiam ser tratadas no paradigma dos conflitos de classe, à moda francesa ou inglesa. 0 ra, para começar, a moderna organização social em classes supõe níveis de igualdade social, de pleno emprego e seguridade social muito mais balanceados do que as sociedades latino-americanas atuais podem exibir.

A implicação mais forte do modelo deTilly, todavia, éque ele não nega, ao contrário reafirma, o fato de que se trata de processos que transcorrem moldados por estruturas sociais, econômicas e de personalidade que estão profundamente arraigadas. Assim, a "imposição", o "empréstimo", ou seja, os mecanismos causais, parecem ser contingenciais e referentes a um tempo concreto, tomado arbitrariamente, desligados por assim dizer do fluxo da história.

A cionadas para resolver uma forma de desigual dade, as categorias raciais não parecem ter 0 dom de desfazer as desigual dades sociais emesmo raciais, mas apenas de estabelecer certo equilíbrio de forças entre grupos que lutam, seja para impor um monopólio (o caso inicial da colonização), seja para escapar de um destino imposto por essas mesmas categorias em al gum momento anterior de tempo (o caso pós-colonial).

Resta, finalmente, tocar num ponto crucial do modelo explicativo de Tilly. M esmo que possamos descartá-lo para a análise do modo como as de sigual dades sociais no Brasil passaram a ser percebidas pelos "negros", emes- 
mo que possamos argumentar convincentemente que as categorias raciais "impostas" pelas políticas públicaseram secularmenteatuantesna sociedade brasileira, precisamosresponder à implicação maior do modelo, qual seja: as políticas públicas racializadas, ou multiculturais, não superam ou suprimem as desigualdades por si só, mas apenas as reproduzem num quadro mais claro e preciso. 0 u seja, regulamentam o conflito distributivo em novas bases, sem pôr em risco a reprodução do sistema com um todo.

N esse aspecto, Tilly parece ter razão: não há por que esperar que a nova forma de organização dos atores políticos (em bases étnicas, raciais ou culturais) seja necessariamente mais eficiente para impedir a reprodução das desigual dades sociais.

Referências Bibliográficas

Azevedo, Thales de. (1953), Les élites de couleur dans une ville brésilienne. Paris, Unesco.

BARTH , Frederik. (1994), "Enduring and emerging issues in the analysis of ethnicity".

In: Verme eulen, H ans \& Govers, Cora (eds.), Theanthropology of ethnicity, beyond "Ethnic Groups and Boundaries". Amsterdã, $\mathrm{H}$ et Spinhuis, pp. 11-32.

BASTIDE, Roger \& FERn AN DES, Florestan. (1955), Relações raciais entre negros e brancos em São Paulo. São Paulo, Unesco-Anhembi.

Brysk, Alison \& W ISE, Carol. (1997), "Liberalization and ethnic conflict in Latin America". Studies in Comparative International D evelopment, 32 (2).

Cam pos, M aria José. (2002), Arthur Ramos: luz e sombra na antropologia brasileira: uma versão da democracia racial no Brasil nas décadas de 1930 e 1940. São Paulo. Dissertação de mestrado. Programa de Pós-Graduação em Antropologia Social, FFLCH -USP.

. (2005-2006), "C assiano Ricardo e o 'mito da democracia racial': uma versão modernista em movimento". Revista U SP, 68.

Carvalho, José Murilo de. (2004), "Genocídio racial estatístico". 0 Globo, 27 de dezembro.

FAORO, Raymundo. (1958), Os donos do poder. Rio de Janeiro, Globo.

Feres J R., J oão. (2005), "Ação afirmativa no Brasil: a política pública entre os movimentos sociais e a opinião douta". Trabalho apresentado no Seminário Internacional "Ações afirmativas nas políticas educacionais: o contexto pós-D urban", 20 a 22 de setembro, Brasília.

Fern And Es, Florestan. (1965), A integração do negro na sociedade de classes. São Paulo, Cia. Editora N acional. 
FREYRE, Gilberto. (1933), Casa-grande \& senzala: formação da família brasileira sob 0 regime da economia patriarcal. Rio de Janeiro, Schimidt.

- (1936), Sobrados e mucambos. Rio de Janeiro, Editora N acional.

- (1938), Conferências na Europa. Rio de Janeiro, M inistério da Educação e Saúde.

FRY, Peter. (1995-1996), “O que a C inderela N egra tem a dizer sobre a política racial brasileira". Revista USP, 28: 122-135.

GiLroy, Paul. (1993), The black Atlantic: modernity and double consciousness. Londres/N ova York, Verso.

Gros, Christian. (2000), Políticas de la etnicidad. Identidad, estado y modernidad. Bogotá, ICAN H.

Guimarães, Antonio Sérgio. (1999), Racismo e anti-racismo no Brasil. São Paulo, Editora 34.

.. (2001), "D emocracia racial: o ideal, o pacto e o mito". N ovos Estudos Cebrap, XX (61): 147-162. São Paulo.

. (2002), Classes, raças e democracia. São Paulo, Editora 34.

. (2003), "D émocratie raciale". Cahiers du Brésil Contemporain, 49/50: 11-

38. Paris.

H ALE, Charles. (2002), "D oes multiculturalism menace? G overnance, cultural rights and the politics of identity in Guatemala". Journal of Latin American Studies, 34: 485-524.

H ARRIS, M arvin. (1956), Town and country in Brazil. N ova York, Columbia University Press.

H asen balg, Carlos. (2005), "Estrutura de classes, estratificação social e raça”. In: . Discriminação e desigualdades raciais no B rasil. 1a edição 1979. São PauIo, H umanitas, cap. 3.

H asenbalg, C. \& Silva, N. V. (1988), Estrutura social, mobilidade e raça. Rio de Janeiro, Vértice/luperj.

. (1992), Relações raciais no Brasil contemporâneo. Rio de Janeiro, Rio Fundo Editora.

H IRSCHMAN, Albert O . (1991), The rhetoric of reaction: perversity, futility, jeopardy. Cambridge, M ass., Belknap Press of $\mathrm{H}$ arvard University Press.

H o LAN D A, Sérgio Buarque de. (1936), Raízes do Brasil. Rio de Janeiro, José O lympio.

LEAL, M aria das Graças de Andrade. (2004), M anuel Querino entre letras e lutas Bahia: 1851-1923. São Paulo. Tese de doutorado em H istória. Pontifícia Universidade Católica.

M ACED O, M árcio. (2006), Abdias do N ascimento: a trajetória de um negro revoltado: 1914-1968. São Paulo. D issertação de mestrado em Sociologia. FFLCH -USP. 
M AGgIE, Yvonne. (1996), "Aqueles a quem foi negada a cor do dia: as categorias de cor e raça na cultura brasileira". In: MAIO, Marcos C. \& SAntos, Ricardo V. (orgs.), Raça, ciência e sociedade. Rio de Janeiro, Fiocruz/C entro Cultural Banco do Brasil.

N ascimento. Elisa L. (2003), 0 sortilégio da cor. São Paulo, Summus.

Petruccelli. José. (2006), “Classificação étnico-racial brasileira: onde estamoseaonde vamos". REAA, Textos para D iscussão número 1.

Pierson, Donald. (1971), Brancos e pretos na Bahia (estudo de contacto racial). 1a edição 1942. São Paulo, Editora N acional.

Police, Gerard. (2000), Abdias do N ascimento: I'afro -brésilien reconstruit. 1914-1944. França. Tese de doutorado. D épartement de Portugais, Université Rennes 2, $\mathrm{H}$ aute Bretagne, 2 vols.

Przeworski, Adam. (1985), Capitalism and social democracy. Cambridge, Cambridge University Press.

Santos, Joel Rufino dos. (1985), "O movimento negro e a crise brasileira”. Política e Administração, 2 (2): 287-307. Rio de Janeiro, jul./set.

Schwarcz, Lilia. (1999), "Q uestão racial e etnicidade”. In: M ICELI, Sérgio. (org.), 0 que ler na Ciência Social brasileira (1970-1995). Vol. 1: Antropologia. São Paulo, Sumaré/Anpocs, pp. 267-326.

SILva, N elson do Valle. (1978), White-nonwhite income diferentials: Brazil 1960. PhD Thesis. University of M ichigan.

SoAREs, Sergei. (2000), "O perfil da discriminação no mercado de trabal ho: homens negros, mulheres brancas e mulheres negras". I pea, Textos para discussão número 769.

Telles, Edward. (2003), Racismo à brasileira. Rio de Janeiro, Relume-D umará.

TILly, Charles. (2003a), "Social boundaries mechanisms". D raft paper for symposium on social mechanisms, Philosophy of Social Sciences. . (2003b), "H istorical perspectives on inequality". D raft chapter for M ary Romero e Eric M argolis (eds.), Blackwell Companion to Social Inequalities.

V an Cott, Donna Lee. (2000), The friendly liquidation of the past: the politics of diversity in Latin America. Pittsburgh, University of Pittsburgh Press.

ViotTI dA Costa, Emilia. (1985), "The myth of racial democracy: a legacy of the Empire". In: . The Brazilian Empire, myths and histories. Belmont, CA, Wadsworth Publishing Company.

W AgLey, Charles (org.). (1952), Race and class in rural Brazil. N ova York, Columbia University Press. . (1960), Revolução brasileira: uma análise da mudança social desde 1930. Salvador, Progresso Editora. 
YASH AR, D eborah. (1999), “D emocracy, indigenous movements, and the postliberal challenge in Latin America". World Politics, 52 (1).

\section{Resumo}

Depois da democracia racial

N este artigo, meu objetivo é refletir sobre um cenário futuro, que se torna cada vez mais real epróximo: aquele em que as desigualdades raciais no Brasil convivem com um regime de Estado do qual as organizações negras e outras organizações populares participam ativamente na formulação de políticas multiculturalistas e no qual a ideologia da democracia racial cessou de ser hegemônica. Se, por um lado, nesse cenário, ganhamos efetiva consciência das limitações de nossa democracia, da heterogeneidade da nossa formação e da insidiosa reprodução das desigual dades raciais, nem por isso somos capazes de reverter esse quadro. Essa éa oportunidade de expor al guns equívocos interpretativos atualmente correntes na literatura: nem as desigual dades raciais resultam da "democracia racial", nem a reprodução das desigualdades pode ser explicada pela simples existência de categorizações de base racial.

Palavras-chave: D emocracia racial; D esigualdades raciais; M ulticulturalismo; Estado popular.

\section{Abstract}

After racial democracy

In this article, I trace a scenario that is becoming increasingly actual and close to Brazilians. In that scenario racial inequalities coexist with a popular state regime in which Black N GO s participate in the implementation of multicultural policies and racial democracy ceases to be a hegemonic discourse. We have acquired consciousness of the limitations of our democracy, of the multicultural nature of our national formation, and of our invidious system of racial inequalities, but we are not successful in stopping it from reproducing itself. I take this scenario as an occasion to point to two current misinterpretations in the sociological literature: neither are racial inequalities in Brazil the product of racial democracy, neither can racial inequalities result from the mere existence of racial categories.

Keywords: Racial democracy; Racial inequalities; Multiculturalism; Popular State.

Antonio Sérgio Alfredo Guimarães é professor de sociologiana Universidade de São Paulo. E-mail: asguima @usp.br. 